\title{
Abstract
}

\section{Role of Rapid Response Teams in Response to Outbreaks in Yemen, 2020: Descriptive Study}

\author{
Abdulqawi Qaserah ${ }^{1}$; Labiba Anam ${ }^{2}$; Reema Alyosfi $^{2}$ \\ ${ }^{1}$ Ministry of Public Health and Population, Sana'a City, Yemen \\ ${ }^{2}$ Yemen Field Epidemiology Training Program, Sana'a City, Yemen
}

\section{Corresponding Author:}

Abdulqawi Qaserah

Ministry of Public Health and Population

Al Hasaba Street

Sana'a City

Yemen

Phone: 967772435532

Email: aabuhosam33@gmail.com

\begin{abstract}
Background: Yemen has been increasingly reporting public health emergencies (eg, cholera). The Ministry of Public Health and Population (MoPH\&P) has put in place the Rapid Response Teams (RRTs) mechanism from the national to district level to investigate and initiate the response to public health emergencies. An RRT is a technical, multidisciplinary team that is readily available for quick mobilization and deployment in case of emergencies.

Objective: The aim of this analysis was to summarize the role of RRTs in response to outbreaks in Yemen during 2020.

Methods: Data were obtained from the electronic Diseases Early Warning System (eDEWS) in Excel format covering the period from January to December 2020, including governorates, diseases, and other variables. Data were cleaned and analyzed using Excel 2013. Qualitative data are summarized as percentages. Data are presented using tables, graphs, and maps.

Results: A total of 39,451 field descents were performed. Nearly half of the activities ( $\mathrm{n}=18,565,47.06 \%)$ were for outbreak investigation of various infectious diseases, including cholera $(n=9030)$, severe acute respiratory infection $(n=1949)$, diphtheria $(n=1532)$, measles $(n=1328)$, malaria $(n=1012)$, dengue fever $(n=1008)$, pertussis $(n=803)$, mumps $(n=676)$, chickenpox $(n=583)$, acute flaccid paralysis $(\mathrm{n}=482)$, and meningitis $(\mathrm{n}=162)$. Approximately $1747(4.43 \%)$ supervision visits were implemented. Regarding health education, 19,139 (48.51\%) health education sessions were executed, with 3419 (17.86\%) performed at health facilities and 15,720 (82.14\%) performed outside health facilities (eg, schools and outdoors). A total of 559,805 people attended the health education sessions.

Conclusions: RRTs support the MoPH\&P in reducing or "slowing down" disease transmission as quickly as possible through various activities such as outbreak investigations and health education. Therefore, there is a strong need to continue supporting the RRTs financially and logistically by donors. In addition, governmental financial support to the RRTs is highly recommended to ensure the sustainability of the program.
\end{abstract}

(iproc 2022;8(1):e36485) doi: $10.2196 / 36485$

\section{KEYWORDS}

RRT; roles; activities; Yemen; 2020 
Edited by Y Khader; this is a non-peer-reviewed article. Submitted 16.01.22; accepted 19.01.22; published 04.02.22.

Please cite as:

Qaserah A, Anam L, Alyosfi R

Role of Rapid Response Teams in Response to Outbreaks in Yemen, 2020: Descriptive Study iproc 2022;8(1):e36485

URL: https://www.iproc.org/2022/1/e36485

doi: $\underline{10.2196 / 36485}$

PMID:

(C)Abdulqawi Qaserah, Labiba Anam, Reema Alyosfi. Originally published in Iproceedings (https://www.iproc.org), 04.02.2022. This is an open-access article distributed under the terms of the Creative Commons Attribution License (https://creativecommons.org/licenses/by/4.0/), which permits unrestricted use, distribution, and reproduction in any medium, provided the original work, first published in Iproceedings, is properly cited. The complete bibliographic information, a link to the original publication on https://www.iproc.org/, as well as this copyright and license information must be included. 